\title{
Numerical simulation of combustion distribution in a gas burner
}

\author{
Ming Bao ${ }^{1, a^{*}}$, Jiming $\operatorname{Lin}^{1, b}$ \\ ${ }^{1}$ College of Mechanical Engineering and Automation, Huaqiao University, Xiamen, Fujian Province, China
}

\begin{abstract}
The combustion effect of natural gas-air mixed combustion is optimised through an effective and rational design of the burner structure, thereby reducing the emission of atmospheric pollutants and achieving energy saving and emission reduction. This paper starts from the geometric model of the burner and uses Computational Fluid Dynamics (CFD) technology to numerically simulate the combustion distribution in the burner, which results in the combustion distribution of the burner after optimising the structure. The guiding effect of the blower guide vanes on the airflow is weak, and the back pressure effect of the guide vanes mounting body is significant, which reduces the primary air volume and prolongs the combustion history in the central region of the flame; The temperature field is evenly distributed and the combustion is well distributed; $\mathrm{CH}_{4}$ and $\mathrm{CO}$ in the furnace chamber are basically burned out and the NO concentration in the furnace chamber is about $800 \mathrm{ppm}$, which basically meets the emission standard and the combustion effect is good. This paper has certain guiding significance for the study of burner structure.
\end{abstract}

\section{Introduction}

In recent years, there has been an explosive growth in the use of gas burners as a complement to mixture equipment. A gas burner is the collective name for a device that causes natural gas and air to be ejected in a certain way and mixed for combustion ${ }^{[1]}$. The flue gas produced by the combustion of the burner contains the atmospheric pollutant NOx. With the strict policy of energy saving and emission reduction, the requirements for NOx emission limits in industrial flue gas are getting higher and higher. Therefore, through effective and rational design of the burner structure, the proportionality and uniformity of distribution of natural gas and air are optimised to improve the combustion effect of the burner combustion and thus reduce the NOx emissions ${ }^{[2]}$. With the rapid development of computer technology and numerical computing, more and more scholars are conducting numerical simulations and analytical studies on the combustion distribution and combustion effects of gas burners based on Computational Fluid Dynamics (CFD) technology. One of the most popular commercial CFD software is FLUENT, which features rich physical models, advanced numerical methods and powerful preand post-processing capabilities, and is widely used in the field of numerical simulation of combustors ${ }^{[3,4]}$.

Sheng Chen et al. ${ }^{[5]}$ propose an improved solution for a low NOx strategy based on a fuel-segmented natural gas burner. The modelling results of the burner are analysed using the commercial CFD software FLUENT, and it is concluded that the improved folded burner can significantly and consistently reduce the NOx content. Antonio Andreini et al. ${ }^{[6]}$ have carried out a numerical analysis of the premixed burner with a cross-flow jet structure in the premixed injection system in order to achieve homogeneous mixing of fuel and air. A.Andreini et al. ${ }^{[7]}$ have used the Reynolds Averaged Navier-Stokes (RANS) and CFD method to numerically analyse the internal premixing process of the combustor, modifying the fuel injection criteria and fuel splitting to minimise exhaust gas NOx emissions. Zakaria Mansouri et al. ${ }^{[8]}$ have studied numerically the non-premixed flame of the burner cyclone by RANS calculations, Delayed-Detached Eddy Simulation (DDES) and experimental measurements. Yichao Li et al. ${ }^{[9]}$ studied the combustion performance of slotted and unslotted cyclones in the burner by measuring the $\mathrm{CO}_{2}$ emission concentration values and carried out a numerical study, which concluded that slotted cyclones have the potential to improve the combustion performance of the combustion chamber. Other authors have carried out computational fluid dynamics simulations of the flow in burners burning gaseous fuels, leading to numerical analyses of the combustion effects of different configurations of burners ${ }^{[10]}$.

From the research results of excellent scholars, it can be concluded that the structure of an effective and reasonable gas burner has a decisive role in the combustion distribution and low NOx exhaust emissions $^{[11]}$. Based on many considerations mentioned above, this paper proposes a gas multi-level burner and conducts a numerical study of its combustion distribution and combustion effect. Through FLUENT software simulation, the values of airflow distribution, fuel uniformity and temperature field distribution are explored to judge the effect of its combustion, and the research results have certain reference value for the

*e-mail: 20014080002@stu.hqu.edu.cn 
combustion distribution of gas burners.

\section{Numerical simulation methods}

\subsection{Burner model}

The gas burner consists of a blower, a gas pipe, a flame holder and a furnace chamber. A three-dimensional diagram of the burner is shown in Figure 1. The blower has special deflector blades to produce a certain acceleration effect on the airflow, the schematic diagram of the blower is shown in Figure 2. The flame holder consists of a two-stage cyclone blade, which is installed at an angle of 30 degrees, as shown in Figure 3. In the flame holder, the first stage cyclone blade is fed with primary air, the second stage cyclone blade is fed with secondary air and the air flow outside the rotating flow outer ring is fed with tertiary air.

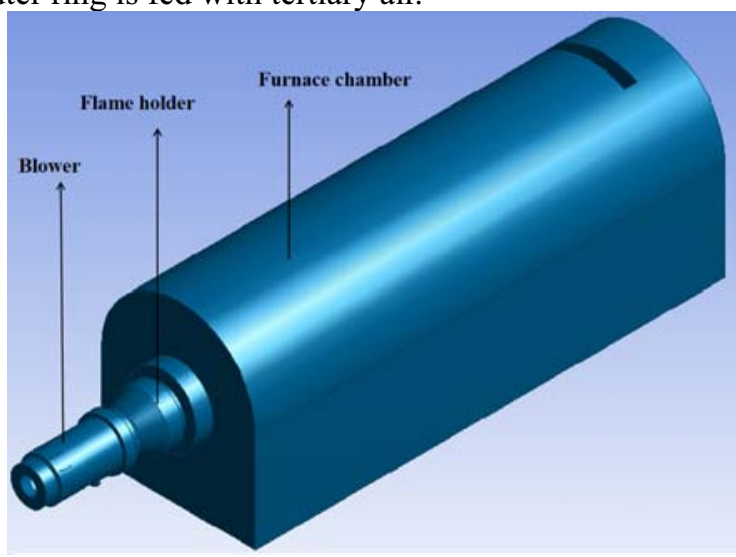

Figure 1. Three-dimensional diagram of the gas burner

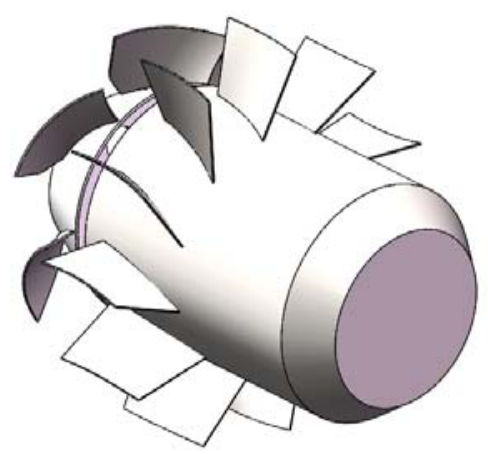

Figure 2. Structure of a blower guide vanes

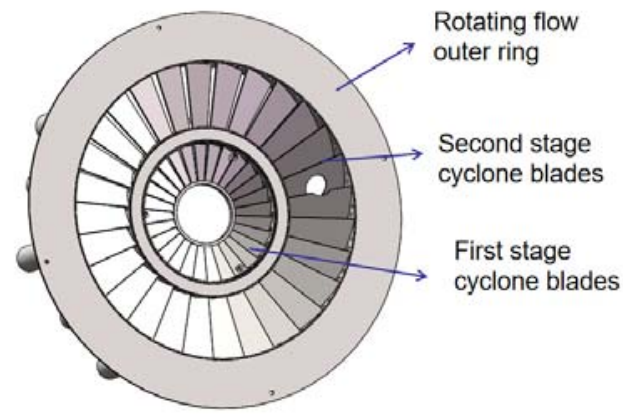

Figure 3. Structure of a flame holder

\subsection{Calculation grids}

Due to the irregular shape of the geometric model, a non-structural tetrahedral mesh was used for fine meshing before numerical calculations, with a total mesh size of approximately 9.04 million, as shown in Figure 4, with a minimum mesh size of $1 \mathrm{~mm}$, Element Quality of grids is greater than 0.2, Skewness is less than 0.85, Orthogonal Quality is more than 0.2, and the Aspect Ratio is more than 1.6. This numerical calculation divides the entire fluid domain into three parts: the hood air section into AirPart, the hood gas section into $\mathrm{CH}_{4}$ Part and the furnace chamber into FurnacePart.

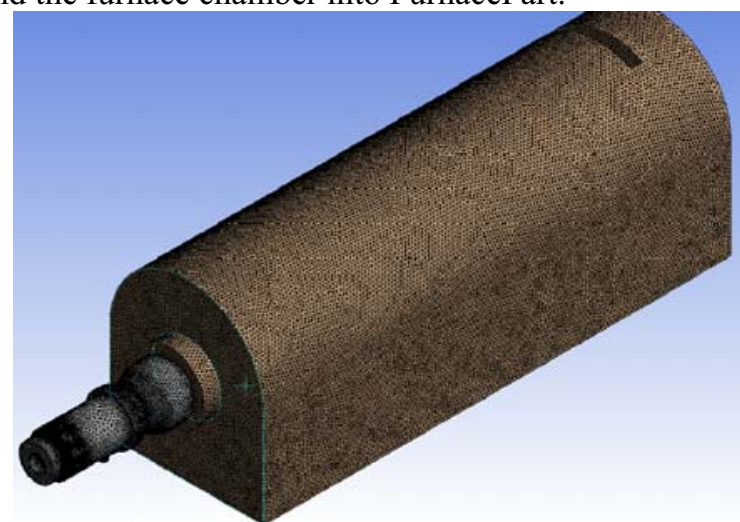

Figure 4. 3D mesh of the computational domain of the gas burner

\subsection{Boundary conditions}

The negative pressure in the furnace chamber is $65 \mathrm{~Pa}$, the burner load is $50 \%$, the gas flow rate is $1575 \mathrm{~m}^{3} / \mathrm{h}$, the air flow rate is the gas flow rate multiplied by 1.35 , $2165.25 \mathrm{~m}^{3} / \mathrm{h}$ and a fan speed of $1522 \mathrm{r} / \mathrm{min}$. The boundary conditions are calculated based on the input flow rate and the cross-sectional area of the air inlet and methane inlet, where the air inlet velocity is $18.92 \mathrm{~m} / \mathrm{s}$ and the methane inlet velocity is $28 \mathrm{~m} / \mathrm{s}$.

\subsection{Calculation processes}

The first part is the calculation of the cold flow field in the fluid domain. The second part of the combustion field 
calculation is carried out by setting the outlet pressure until the pressure at the monitoring point of the furnace equals $-65 \mathrm{~Pa}$, until the volumetric reaction calculation converges and then the third part of the radiation field calculation is carried out ${ }^{[12]}$.

\section{Simulation results and discussion}

Numerical simulations were carried out to investigate the combustion temperature distribution and combustion effect of this burner and the effect of each part of the burner on the combustion effect, the following sections are the results of this investigation.

\subsection{Analysis of the effect of blower guide vanes on airflow distribution}

The blower's guide vanes have a special structure, the guide vanes are evenly distributed along the circumference, under the action of the blower, the airflow has an obvious role in promoting the combustion effect. Blower pressure distribution diagram in Figure 5, the different positions of the guide vanes on the distribution of airflow is influential, from Figure 5 can be seen in the guide vanes of the pressure surface and suction surface pressure difference is approximately equal to $150 \mathrm{~Pa}$, airflow in the suction surface to form a certain wall effect, with a certain acceleration effect.

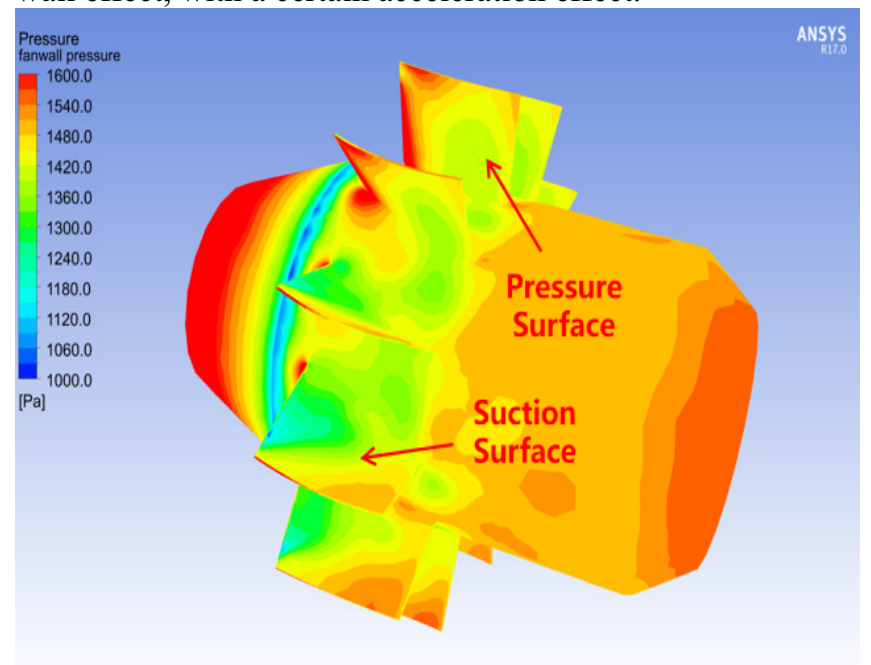

Figure 5. Blower pressure distribution

\subsection{Analysis of the uniformity of fuel distribution by layered and evenly distributed spray holes}

The arrangement of the gas injection holes has a significant effect on the fuel distribution uniformity, and this burner uses a layered and even distribution of the injection holes to analyse the fuel distribution uniformity. A comparison of the $\mathrm{CH}_{4}$ distribution analysis was carried out by taking a cross-section behind the flame holder and a Y-section of the cold and hot flow fields, as shown in Figure 6 and Figure 7. The results show that the methane is more uniformly distributed in the cold flow field with a weighted average mass equal to approximately 0.1 , while in the hot flow field the methane is completely burned in the large blade area with a surface weighted average mass fraction equal to approximately 0.03 .

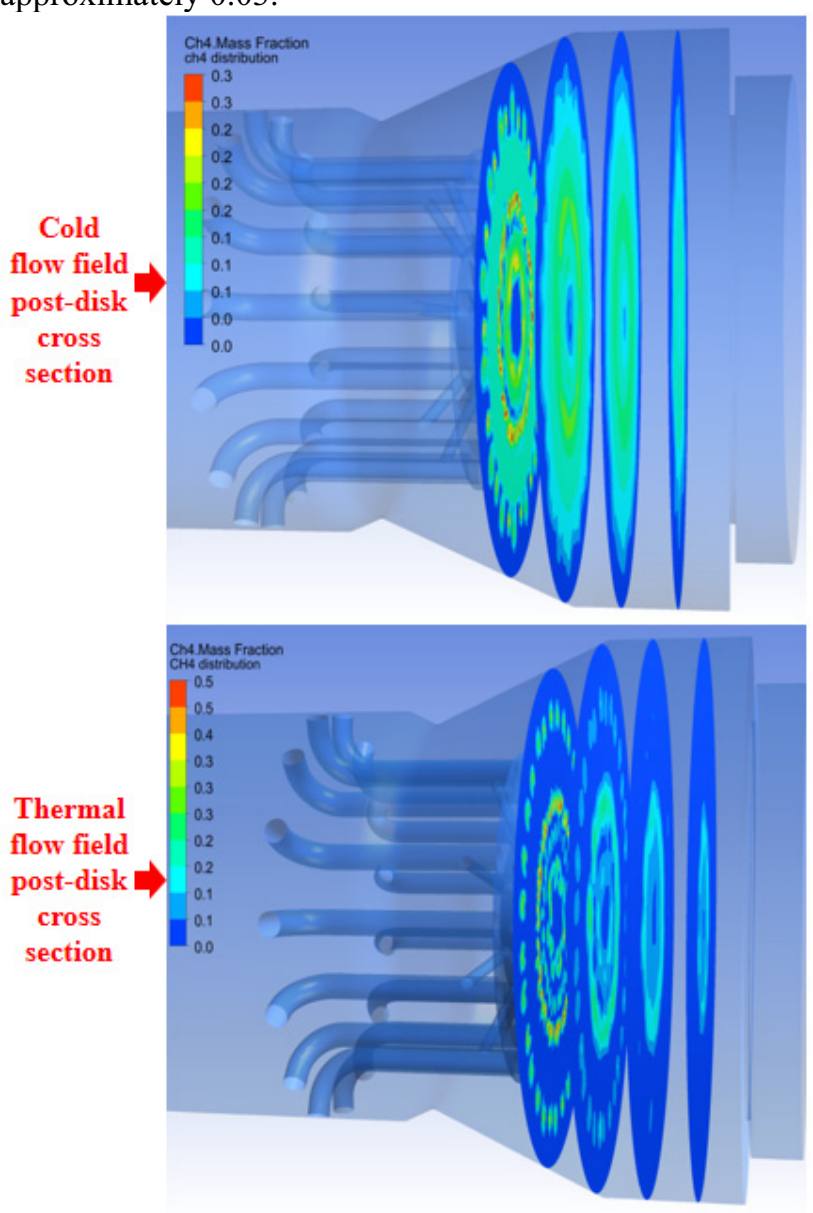

Figure 6. $\mathrm{CH}_{4}$ distribution 

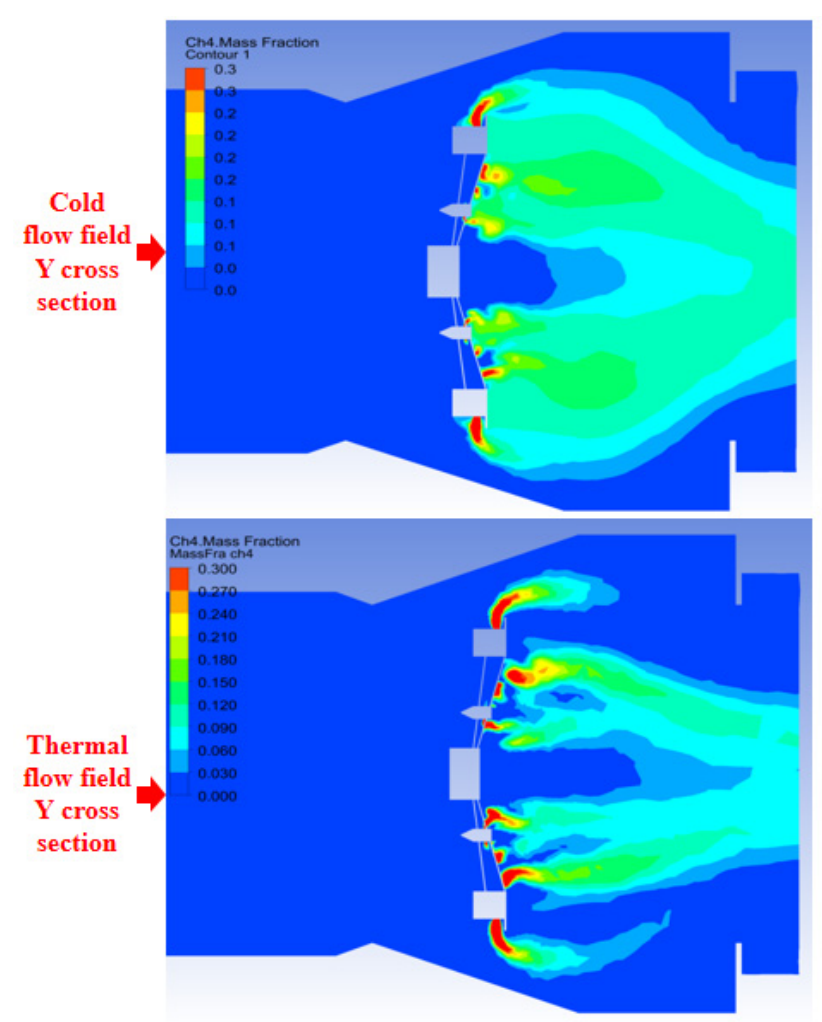

Figure 7. $\mathrm{CH}_{4}$ distribution

\subsection{Strength analysis of cyclonic vane return flow}

The calculation after the simulation can be found that the total air volume is about $17800 \mathrm{~m}^{3} / \mathrm{h}$ and the primary air volume is about $2867.8 \mathrm{~m}^{3} / \mathrm{h}$. It is calculated that the primary air volume accounts for $16.1 \%$ of the total air volume and the air flow in the area of the flame holder is rotating forward and there is no return flow, as shown in Figure 8 . The airflow is mainly diffused along the axial direction, away from the disc surface, while there will be radial convection due to the contraction of the channel.

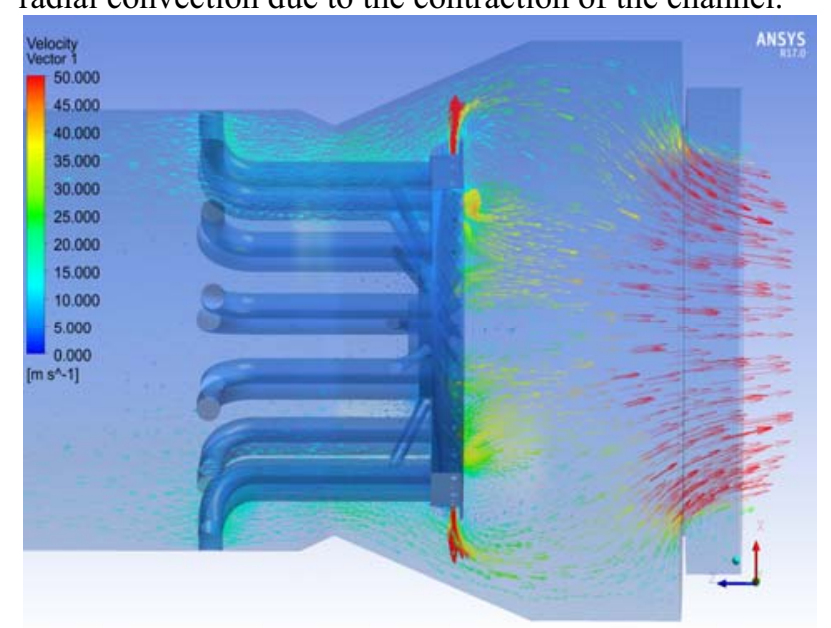

Figure 8. Rotational velocity vector

\subsection{Temperature field uniformity analysis}

Analysis of the temperature field uniformity, if the temperature field is "high above and low below", "low above and high below" and other uneven results will cause the high temperature area to promote the production of NOx, so that the NOx emission concentration at the exit of the furnace is high. This will reduce the combustion effect of the burner, resulting in inadequate combustion, combustion shift and other phenomena. The uniformity of the temperature field behind the flame holder of this burner can be found from the perspective view, as shown in Figure 9, the temperature distribution around the entire flame holder is uniform, with the temperature range roughly between $1500 \mathrm{~K}$ and $1800 \mathrm{~K}$, and the combustion distribution is uniform, reducing the NOx concentration generated in the high temperature region.

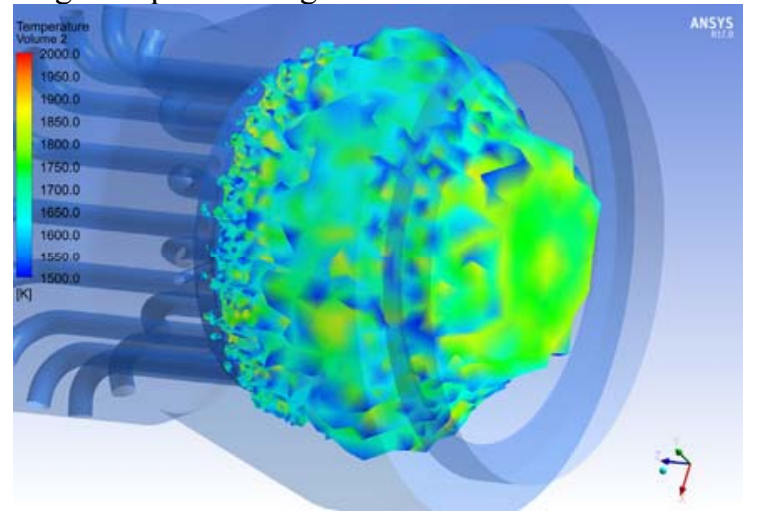

Figure 9. Perspective view of the distribution behind the flame holder

\subsection{Distribution of combustion field products}

The short contact time between gas and air and the uneven mixing result in inadequate combustion, which not only wastes energy and pollutes the environment, but also has a low flame temperature during combustion, making it unsuitable for high temperature production sites. This makes it extremely important to investigate a burner that is safe, burns thoroughly, has high combustion efficiency and has a low NOx emission concentration. We therefore carry out numerical calculations to determine whether the combustion is adequate and effective in terms of the residual of the fuel, the distribution of the combustion products. And we can see the distribution of $\mathrm{CH}_{4}$ and $\mathrm{CO}$ in the burner chamber as shown in Figure 10 and Figure 11, and the distributivity of the combustion products NO as shown in Figure 12, where the concentration of $\mathrm{NO}$ in each part of the chamber can be clearly observed. 


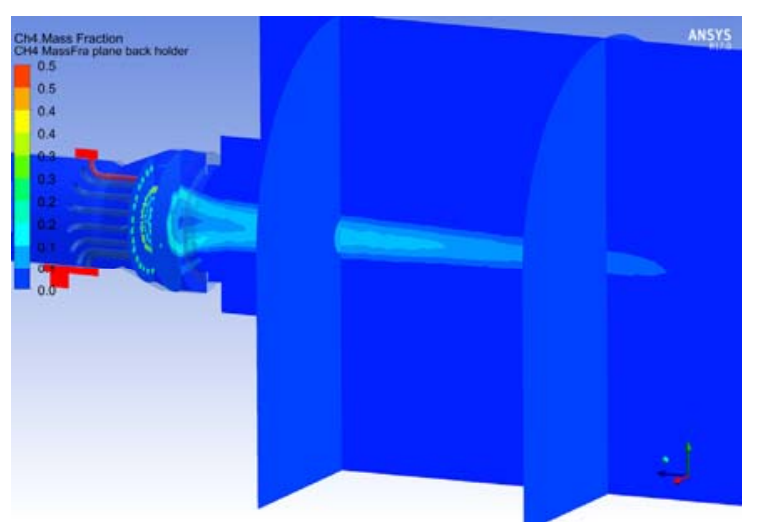

Figure 10. $\mathrm{CH}_{4}$ distribution of cross sections in $\mathrm{X}=0$

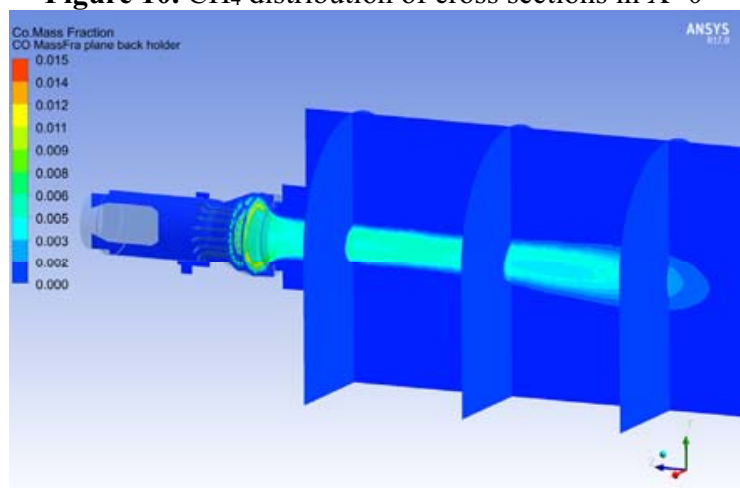

Figure 11. $\mathrm{CO}$ distribution of cross sections in $\mathrm{X}=0$

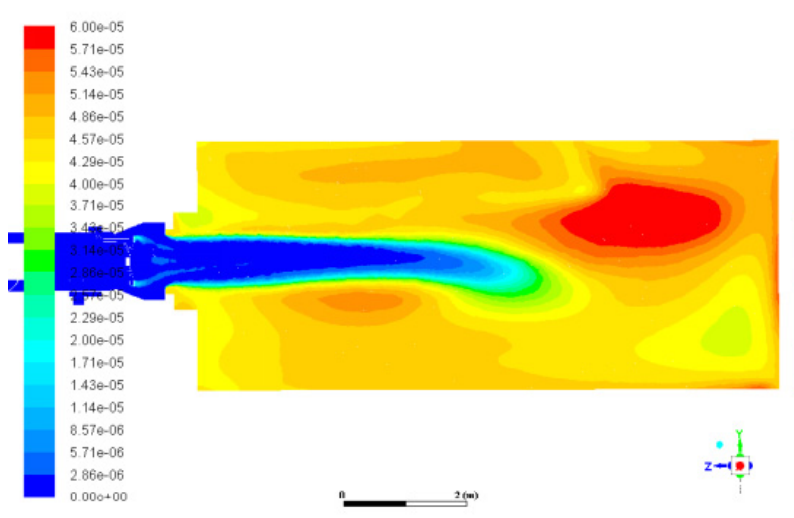

Figure 12. NO distribution of cross sections in $X=0$

\section{Conclusion}

(1) By observing the blower guide vanes on the airflow distribution of the impact analysis chart, the blower guide vanes on the airflow guidance role is weak, guide vanes installed body back pressure effect is significant, reduce the primary air volume, primary air volume of about $16.1 \%$ of the total air volume, where the steady flame disc blade of the cyclonic airflow forward, no backflow.

(2) As can be seen from the structure of the flame holder, there are gas spray holes distributed on the inside and outside of the small and large flame holder blades, and the gas is mainly diffused in the cross-section in the axial direction; also due to the reduction of the primary wind speed, the mixing time of the fuel in the central area of the small blades is extended to prolong the combustion history in the central area of the flame.

(3) From the circumferential temperature distribution of the flame holder, it can be concluded that the temperature field in the large blade area and the outer edge area of the flame holder is evenly distributed, with the temperature in the range of $1200^{\circ} \mathrm{C} \sim 1600^{\circ} \mathrm{C}$ or so, and the combustion distribution is good. The $\mathrm{CH}_{4}$ and $\mathrm{CO}$ in the furnace chamber are basically burnt out, and the NO concentration in the furnace chamber is about $800 \mathrm{ppm}$, which is about $32 \mathrm{mg} / \mathrm{m}^{3}$, which basically meets the standard of emission and has a good combustion effect.

\section{Acknowledgments}

This work was financially supported by the Pilot Project of Fujian Province (2018H0021).

\section{References}

1. iguo Zhou, Junying Tang, et al. Design optimization and CFD evaluation of a volute swirl burner with Steven R Mickey, Martin G Schönfelder, Joachim G Wünning. Direct-Fired Gas Burners for High Temperature Applications[J]. Industrial Heating, 2019, 87(10).

2. Murat Umut YANGAZ, Gökçen Alev ÇİFTÇİOĞLU, Mehmet Arif Neşet KADIRGAN. Effects of Different Applications and Designs on Emission Reduction in a Gas Burner. 2018, :218-226.

3. [1]Yunfei Jia, Wecentral gas supply[J]. Journal of the Brazilian Society of Mechanical Sciences and Engineering, 2020, 42(1-2).

4. [1]Minsung Choi, Yonmo Sung, Myungjun Won, et al. Effect of fuel distribution on turbulence and combustion characteristics of a micro gas turbine combustor[J]. Journal of Industrial and Engineering Chemistry, 2016.

5. Sheng Chen, Yuming Xing, Aojin Li. CFD investigation on Low-NOx strategy of folded flame pattern based on fuel-staging natural gas burner[J]. Applied Thermal Engineering, 2017, 112.

6. Antonio Andreini, Bruno Facchini, et al. Numerical Analysis of a Low NOx Partially Premixed Burner for Industrial Gas Turbine Applications[J]. Energy Procedia, 2014, 45.

7. A. Andreini, M. Cerutti, B. Facchini, A. Innocenti. CFD Analysis of NOx Emissions of a Natural Gas Lean Premixed Burner for Heavy Duty Gas Turbine[J]. Energy Procedia, 2015, 81.

8. Zakaria Mansouri, Toufik Boushaki. Experimental and numerical investigation of turbulent isothermal and reacting flows in a non-premixed swirl burner[J]. International Journal of Heat and Fluid Flow, 2018, 72.

9. Yichao Li, Renfu Li, Dinggen Li, et al. Combustion characteristics of a slotted swirl combustor: An experimental test and numerical validation[J]. International Communications in Heat and Mass Transfer, 2015, 66.

10. K. Khanafer, S.M. Aithal. Fluid-dynamic and NOx 
computation in swirl burners[J]. International Journal of Heat and Mass Transfer, 2011, 54(23).

11. Xuren Zhu, Renfu Li, Dinggen Li, et al. Experimental study and RANS calculation on velocity and temperature of a kerosene-fueled swirl laboratory combustor with and without centerbody air injection[J]. International Journal of Heat and Mass Transfer, 2015, 89.

12. Aleksandra Kiedrzyńska, Robert Lewtak, et al. Numerical study of natural gas and low-calorific syngas co-firing in a pilot scale burner[J]. Energy, 2020, 211. 